\title{
Structural Safety Analysis Based on Seismic Service Conditions for Butterfly Valves in a Nuclear Power Plant
}

\author{
Sang-Uk Han, Dae-Gyun Ahn, Myeong-Gon Lee, Kwon-Hee Lee, and Seung-Ho Han \\ Department of Mechanical Engineering, Dong-A University, Busan 604-714, Republic of Korea \\ Correspondence should be addressed to Seung-Ho Han; shhan85@dau.ac.kr
}

Received 26 February 2014; Accepted 9 March 2014; Published 11 May 2014

Academic Editors: N. Barsoum, V. N. Dieu, P. Vasant, and G.-W. Weber

Copyright (C) 2014 Sang-Uk Han et al. This is an open access article distributed under the Creative Commons Attribution License, which permits unrestricted use, distribution, and reproduction in any medium, provided the original work is properly cited.

\begin{abstract}
The structural integrity of valves that are used to control cooling waters in the primary coolant loop that prevents boiling within the reactor in a nuclear power plant must be capable of withstanding earthquakes or other dangerous situations. In this study, numerical analyses using a finite element method, that is, static and dynamic analyses according to the rigid or flexible characteristics of the dynamic properties of a 200A butterfly valve, were performed according to the KEPIC MFA. An experimental vibration test was also carried out in order to verify the results from the modal analysis, in which a validated finite element model was obtained via a model-updating method that considers changes in the in situ experimental data. By using a validated finite element model, the equivalent static load under SSE conditions stipulated by the KEPIC MFA gave a stress of $135 \mathrm{MPa}$ that occurred at the connections of the stem and body. A larger stress of $183 \mathrm{MPa}$ was induced when we used a CQC method with a design response spectrum that uses $2 \%$ damping ratio. These values were lower than the allowable strength of the materials used for manufacturing the butterfly valve, and, therefore, its structural safety met the KEPIC MFA requirements.
\end{abstract}

\section{Introduction}

The availability factor of nuclear power plants has been significantly improved worldwide, whereby nuclear power is becoming more economically competitive with fossil fuels for base-load electricity generation in many countries [1]. Nuclear power accounted for nearly $35 \%$ of domestic production electricity in 2012 and is gradually increasing in dependency [2]. Structural integrity includes valves that can withstand earthquakes and other dangerous situations, because they are used to control cooling waters in the primary coolant loop to prevent boiling within the reactor in a nuclear power plant. An accident due to the leakage of radioactive matters, however, can inflict catastrophic damage on the environment nearby. Therefore, with the enhanced awareness of the potential of an earthquake to cause such damage, qualifying the valves has now become standard practice, that is, establishing their ability to withstand a seismic load without damage. Strict safety guidelines should be carried out as defined by the KEPIC MFA [3], which indicates the verification of seismic adequacy with prescribed safety rates for structures and equipment. The verification of the seismic adequacy consists of environmental qualifications for handling the effects of heat- and radiation-induced degradation and of seismic qualifications that should be carried out either by numerical analysis or by experimental tests using a shaketable or by comparison with past experiences. The seismic qualification for the use of shake-table testing is normally very exorbitant and these facilities may not be available in many places and can show only single isolated structures or equipment without simulating structural connections to the secondary component, which may change the dynamic behavior when compared with the actual as-installed structures $[4,5]$. Another venerable method for seismic qualification is purely analytical and uses a finite element method. The reliability of this method totally depends on the finite element model, which generally cannot produce the dynamic behavior of as-installed structures even for structurally simple components. Thus, finite element models are usually verified via an experimental modal test. The test results are assumed to be correct and the finite element model is tuned to closely correlate with the experimental test results. In situ modal test data obtained from the modal tests conducted on the asinstalled structure were used directly for the seismic response 


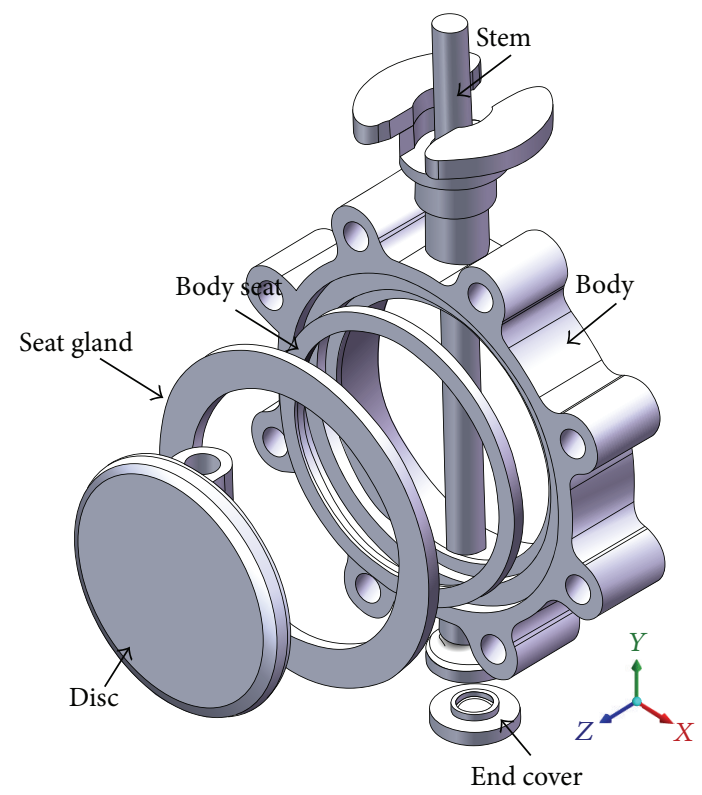

Figure 1: Configuration of a 200A butterfly valve.

estimation in order to overcome the limitations when using a finite element model for seismic analysis $[6,7]$. However, these methods may not always be practical for many of the structural components in a nuclear power plant due to the difficulties of conducting in situ modal tests.

In the present study, the numerical analyses using finite element methods, that is, static and dynamic analyses according to the rigid or flexible characteristics of dynamic properties for a 200A butterfly valve in a nuclear power plant, were performed according to the dictates of the KEPIC MFA [3]. An experimental vibration test was carried out in order to verify the results from the modal analysis, whereby a validated finite element model was obtained via model updating that considered the changes in in situ experimental data. By using the validated finite element model, structural safety analysis under seismic service conditions was carried out.

\section{Seismic Qualification}

2.1. Butterfly Valve. Figure 1 shows the configuration of the butterfly valve, which is used in a nuclear power plant to control cooling waters in the primary coolant loop preventing boiling within the reactor. Since a radiation leak would have a disastrous effect on the environment, the butterfly valve must not leak and must endure earthquakes and other dangerous situations. The butterfly valve shown in Figure 1 has a $200 \mathrm{~mm}$ inner diameter and consists of 6 parts: stem, body, body seat, seat gland, disk, and end cover. These parts are made up of the following materials: Gr. WCB, CF8, T316, T316, A564-630, and T304, respectively.

2.2. Seismic Qualification Process. The seismic qualification of the butterfly valve should demonstrate that the valve has the ability to perform its safety functions during and after being subjected to the forces resulting from a safe shutdown earthquake (SSE) event. The KEPIC MFA [3] describes the approach methods for seismic qualification, which are grouped into 4 general categories: to predict the equipment's performance by numerical analysis, to test the equipment under simulated seismic conditions, to qualify the equipment by a combination of experimental tests and numerical analyses, and to qualify the equipment through the use of experience data. Each of the categories may be adequate to verify the ability of the equipment to meet the seismic qualification requirements. Among these 4 categories, this study focused on predicting the equipment's performance via numerical analysis.

The methods used for numerical analysis include static and dynamic analysis depending on the structure of the equipment and dynamic properties such as the complexity of the equipment and whether the equipment is rigid or flexible [8]. Figure 2 shows the flow chart of a performance assessment based on a seismic qualification using numerical analysis according to the KEPIC MFA [3]. The review stage in the first step takes into account the complexity of the butterfly valve and the adequacy of analytical techniques to properly predict its safe operation during seismic excitation. The butterfly valve should be modeled such that its mass distribution and stiffness characteristics will be adequately represented when using the finite element method. This finite element model can be used to perform a modal analysis in order to determine the rigidity or flexibility. When the natural frequency at the 1st mode calculated by the modal analysis is higher than a cut-off frequency of $33 \mathrm{~Hz}$, that is, the dominant frequency of an earthquake, the butterfly valve is considered sufficiently rigid and may be analyzed statically. But if it is not higher than $33 \mathrm{~Hz}$, a dynamic analysis should be performed because the butterfly valve is considered to be flexible and poses a risk of resonance in the dominant frequency range of an earthquake. In this step, the butterfly valve can be analyzed via response spectrum analysis, in which the responses of stress obtained from each modal response are combined to consider all significant modes. Finally, the structural safety is estimated by comparing the combined stress with the allowable stress of the materials in use.

2.2.1. Static Analysis. Static analysis, also known as equivalent static force analysis, is a method that enables calculation of the stresses in each part of the structure to be recreated by a static force, that is, the equivalent of an earthquake. Although static analysis often underestimates structural safety by comparison with dynamic analysis, this simple process prevents the need to perform time-consuming computations. The acceleration responses that are required in order to estimate structural safety during analysis must be determined only according to the maximum peak of the response spectrum using a conservative damping value. The seismic qualification for unit of equipment devices or structural systems can be achieved only by static analysis, because the effect of resonance does not have to be considered. The governing equation of static analysis can be presented as follows:

$$
[K]\{U\}=\{F\},
$$




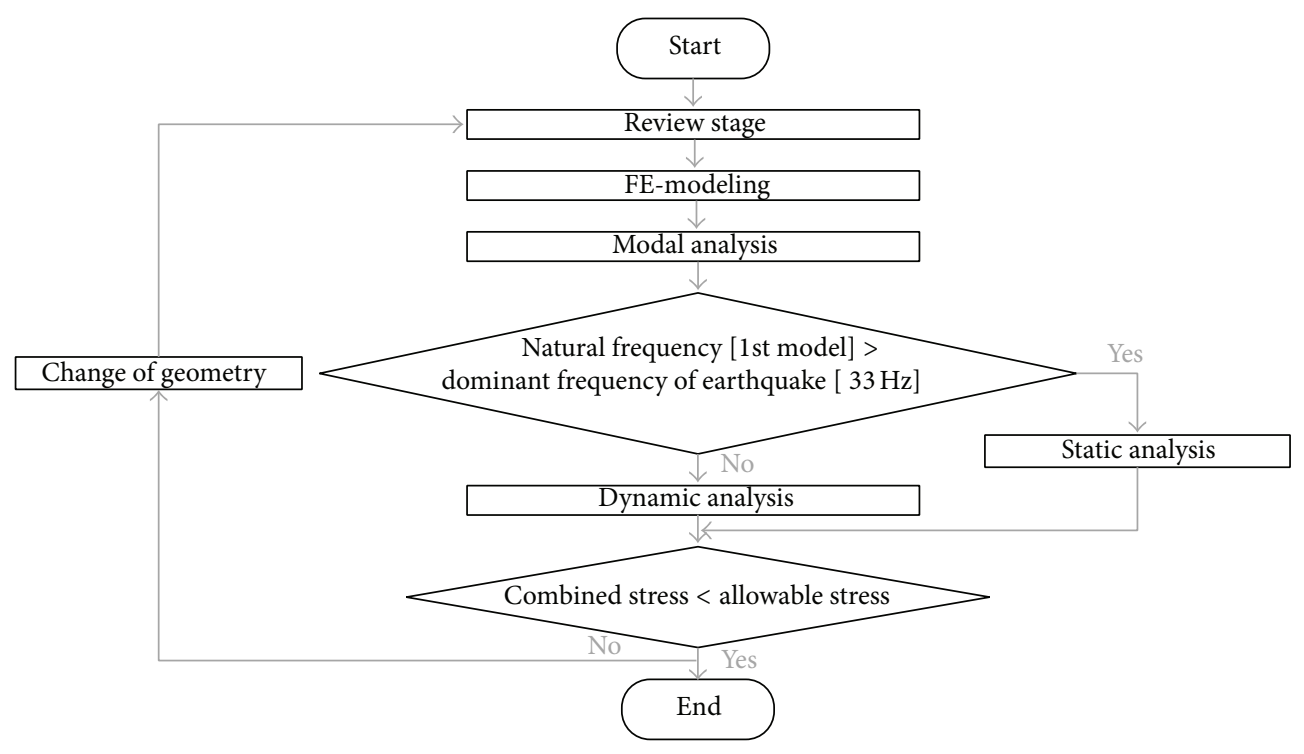

FIGURE 2: Flow chart of performance assessment using numerical analysis.

where $[K],\{U\}$, and $\{F\}$ are designated as the stiffness matrix, the nodal displacement vector, and the external force vector, respectively, caused by the dead load or gross weight. The nodal displacement vector $\{U\}$ was calculated using the finite element method, which then allowed for the stress distribution at nodal points.

2.2.2. Dynamic Analysis. For flexible equipment, where the natural frequency is lower than the dominant frequency of an earthquake, that is, $33 \mathrm{~Hz}$, as shown in Figure 1, dynamic analysis should be carried out based on either the response spectrum method or the time history method. The response spectrum method based on structural dynamics enables the approximate estimation of the dynamic performances of the equipment such as the maximum responses of displacement and stress. The dynamic performances are determined by combining each modal response, which includes all significant modes. This method is commonly used for the dynamic analyses of seismic qualifications. Meanwhile, the time history method can be used to evaluate the time history of dynamic responses due to an earthquake, which displays earthquake-induced motion as a function of time, usually in terms of acceleration. Although the time history method provides relatively accurate dynamic responses, a timeconsuming computational work and a complicated procedure are required due to the consideration of a large number of degrees of freedom and to the detailed data from earthquakeinduced motion $[9,10]$. In the present study, dynamic analysis was conducted using the response spectrum method. The dynamic performances of the equipment can be presented as follows:

$$
[M]\{\ddot{U}\}+[C]\{\dot{U}\}+[K]\{U\}=[P(t)],
$$

where $[M],[C],\{\ddot{U}\},\{\dot{U}\}$, and $[P(t)]$ are the mass matrix, the damping matrix, the nodal acceleration vector, the nodal velocity vector, and the applied dynamic load vector, respectively. In the analysis procedure, the nodal velocity vector of the finite element analysis is obtained first, and then the nodal displacement and stress can be calculated. The modal analysis must be carried out before application of the response spectrum analysis, because $[P(t)]$ is designated as the set of load values induced from the modal responses. After the modal analysis, a response spectrum analysis should be carried out, whereby the responses of stress obtained from each modal response combine all significant modes. There are two rational ways to combine responses from the response spectrum: the SRSS (square root of sum of square) method and the CQC (complete quadratic combination) method [11, 12]. In the SRSS method, the squares of a specific response are summed, and the square root of this sum takes the combined effect into account. The SRSS provides relatively conservative results, except where closely spaced modes apply. In the case of closely spaced modes, the combined response values are often underestimated. Meanwhile, the CQC method combines responses based on the use of crossmodal coefficients, which reflect the duration and frequency content of the seismic events as well as the modal frequencies and damping ratio of the equipment. The present study applied the CQC method. The total mode response, $R_{a}$, obtained by the CQC method can be written as follows:

$$
R_{a}=\left[\sum_{i=1}^{N} \sum_{j=1}^{N} k \varepsilon_{i j} R_{i} R_{j}\right]^{1 / 2},
$$

where $k$ is 1 when $i=j$ is valid and is 2 when $i=j$ is invalid; $R_{i}$ and $R_{j}$ represent the mode responses at the $i$ th and $j$ th modes, respectively. $\varepsilon_{i j}$ designates the cross-modal coefficient presenting the correlation between the $i$ th and $j$ th modes, which can be presented as follows:

$$
\varepsilon_{i j}=\frac{8\left(\xi_{i} \xi_{j}\right)^{1 / 2}\left(\xi_{i}+r \xi_{j}\right) r^{3 / 2}}{\left(1-r^{2}\right)^{2}+4 \xi_{i} \xi_{j} r\left(1+r^{2}\right)+4\left(\xi_{i}^{2}+\xi_{i}^{2}\right) r^{2}},
$$



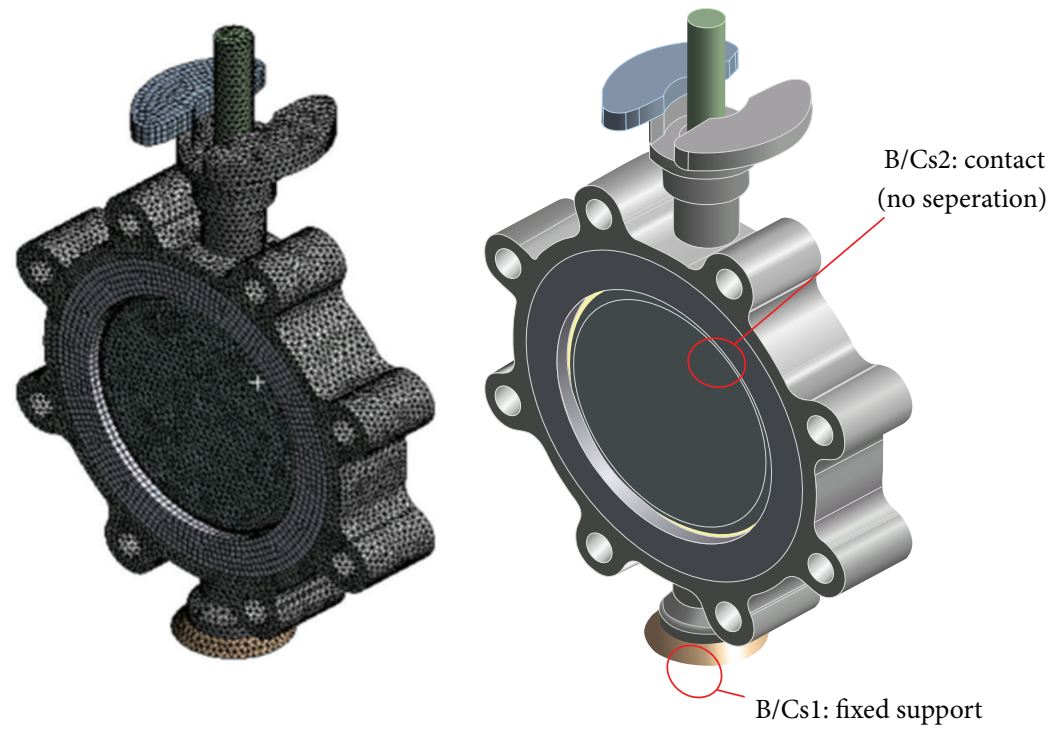

FIGURE 3: Finite element model and boundary conditions for modal analysis based on static analysis.

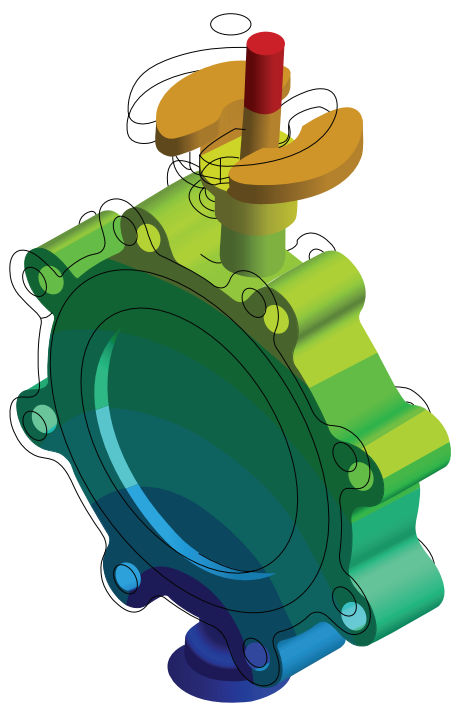

(a) $92.7 \mathrm{~Hz}(1$ st mode)

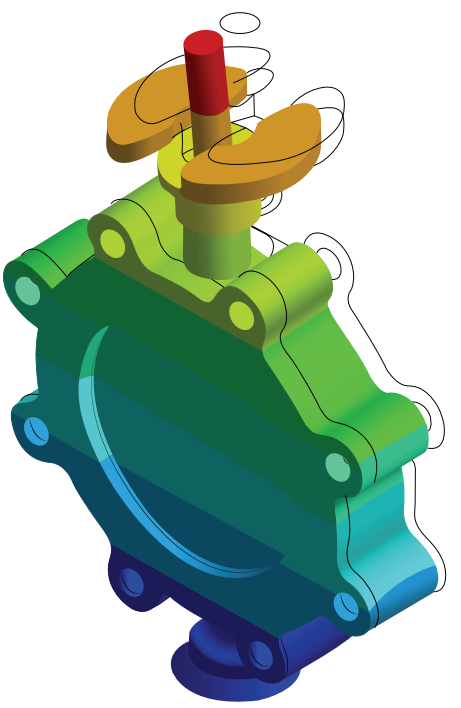

(b) $96.4 \mathrm{~Hz}$ (2nd mode)

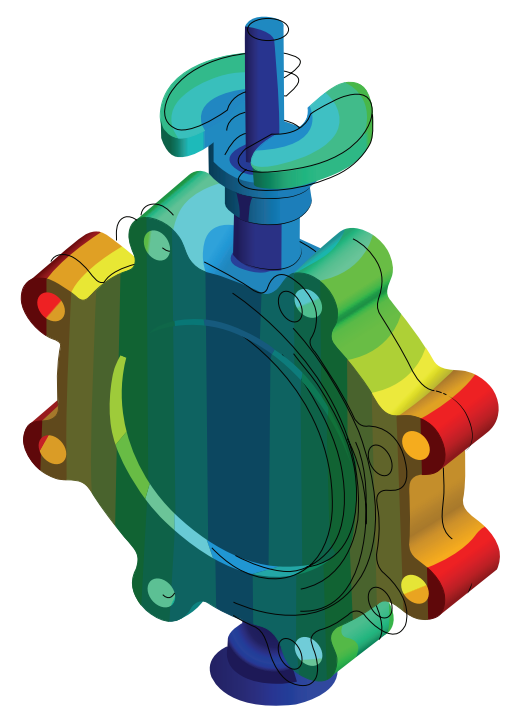

(c) $236.6 \mathrm{~Hz}$ (3rd mode)

FIGURE 4: Frequencies at each mode obtained by modal analysis.

where $r$ and $\xi$ are the ratio of natural frequencies and modal damping, respectively.

\section{Modal Analysis}

3.1. Modal Analysis Using the Finite Element Method. The modal analysis for the butterfly valve was performed using the finite element method via the commercial software, ANSYS Workbench [13]. Figure 3 shows the finite element model constructed using the preprocessor option provided in ANSYS Workbench with the boundary conditions applied to the modal analysis. The contact conditions between each part of the finite element model were implemented using special elements, such as CONTA 174 and TARGE 170, and the noseparation contact boundary condition, where a sliding, but not nonlinear, motion is permitted at the contact surfaces between the disc and body sheet. Furthermore, to investigate the effect of the contact conditions on the frequencies occurring at each mode, other boundary conditions show that the contact surfaces are bonded. Figure 4 shows the natural frequencies obtained by the modal analysis under the no-separation contact boundary conditions, that is, 92.7, 96.4, and $236.6 \mathrm{~Hz}$ at the 1st, 2nd, and 3rd modes, respectively. In the case of the bonded-surface boundary conditions, the modal analysis provided natural frequencies of 94.4, 96.3, and $240.4 \mathrm{~Hz}$ for each mode, which was a less than $2 \%$ error compared with that of the no-separation contact boundary conditions. These results showed that the natural frequencies of the butterfly valve were higher than $33 \mathrm{~Hz}$, which means that the butterfly valve can be considered sufficiently rigid 
TABLE 1: Comparison of natural frequencies obtained using initial and modified FE-models.

\begin{tabular}{|c|c|c|c|}
\hline & 1st mode & 2nd mode & 3rd mode \\
\hline $\begin{array}{l}\text { Natural frequency obtained } \\
\text { from the experimental } \\
\text { modal test }(\mathrm{Hz})\end{array}$ & 69.3 & 72.2 & 219.7 \\
\hline $\begin{array}{l}\text { Natural frequency obtained } \\
\text { by using the initial } \\
\text { FE-model }(\mathrm{Hz})\end{array}$ & $92.7(25 \%)$ & $96.4(25 \%)$ & $236.6(7.7 \%)$ \\
\hline $\begin{array}{l}\text { Natural frequency obtained } \\
\text { by using the modified } \\
\text { FE-model }(\mathrm{Hz})\end{array}$ & $68.9(0.5 \%)$ & $72.3(0.1 \%)$ & $226.6(3 \%)$ \\
\hline
\end{tabular}

() means \% errors (abs.) to natural frequencies obtained from experimental modal test.

and could be analyzed statically according to the process of seismic qualification, as shown in Figure 2.

3.2. Modification of the Finite Element Model. The reliability of the modal analysis totally depends on the finite element model. If the mass distribution and boundary conditions of the finite element model cannot be considered equivalent to the as-installed conditions, the dynamic behavior obtained from the finite element model shows a significant difference compared with the as-installed version. Therefore, the finite element model should be verified using the data from the experimental modal test, in which the test results are assumed to be correct, and the finite element model is tuned to closely correlate with the test results. In the present study, we performed a model-updating method that considered changes in the in situ experimental modal test data, and a validated finite element model was obtained.

An experimental modal test of the butterfly valve was performed. The end cover of the butterfly valve was welded to a steel plate on the reaction floor. The butterfly valve was instrumented with 5 accelerometers from the B\&K Co. [14] with a capacity of 3,000 G, as shown in Figure 5. The location of the accelerometers was selected according to the numerical results from the modal analysis, where 4 accelerometers measured the acceleration at each mode, and the other accelerometer was attached to the steel plate on the reaction floor to compensate for the relative movement of the butterfly valve. Data acquisition was accomplished using NEXUX software from the B\&K Co. Singular values of acceleration data occurred by the stroke of an impact hammer were converted into natural frequencies at each mode. Figure 6 shows natural frequencies of $69.3,72.2$, and $219.7 \mathrm{~Hz}$ at the 1st, $2 \mathrm{nd}$, and $3 \mathrm{rd}$ modes, respectively, and these are listed in Table 1 . As the table shows, the experimental values deviated significantly more than $25 \%$ from the computed frequencies using the initial finite element model. This might have been caused by a poor reflection of the initial finite element model for the butterfly valve such as simplified and idealized assumptions made while constructing the finite element model. For the

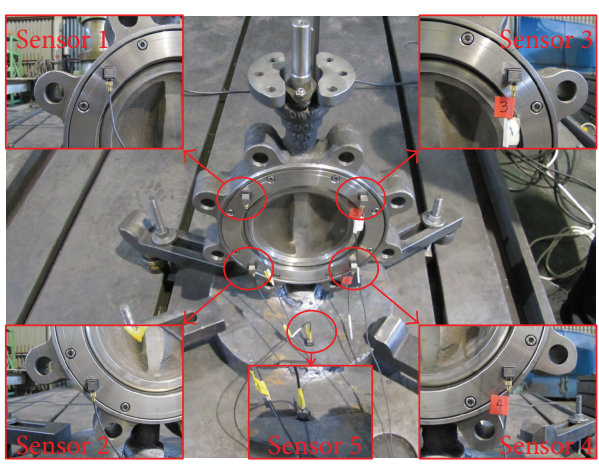

FIGURE 5: Accelerometers attached on the butterfly valve for the experimental modal test.

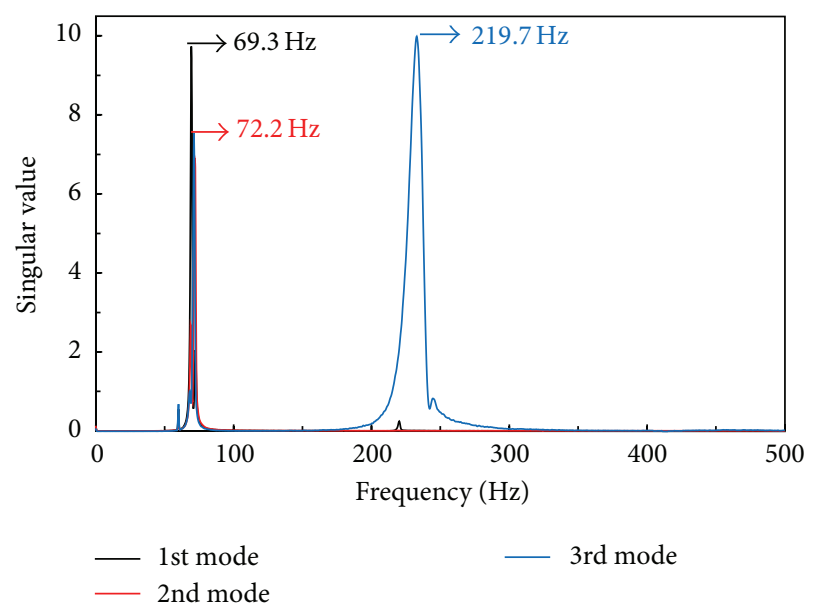

FIGURE 6: Singular values related to the frequencies for each mode.

numerical modal analysis, the butterfly valve was assumed to be rigidly fixed at the steel plate. However, during the experimental modal test, the butterfly valve had either a small degree of rotation or a small deflection at the fixed point. The initial finite element model had to be modified so that it would project confidence for further analysis. To modify the initial finite element model, a trial and error method was used, which is a common part of the model-updating method [15]. Based on the physical understanding of the installation of the butterfly valve, the boundary stiffness at the rigidly fixed steel plate was adjusted, which brought the finite element model predictions close to the experimental results. As shown in Table 1, the computed frequencies from the updated finite element model are almost identical to the measured ones.

\section{Results of the Structural Safety Analysis}

4.1. Static Analysis. The structural safety analysis of the butterfly valve was carried out by the seismic qualification based on the static analysis using the validated finite element model, in which the butterfly valve can be considered rigid due to 


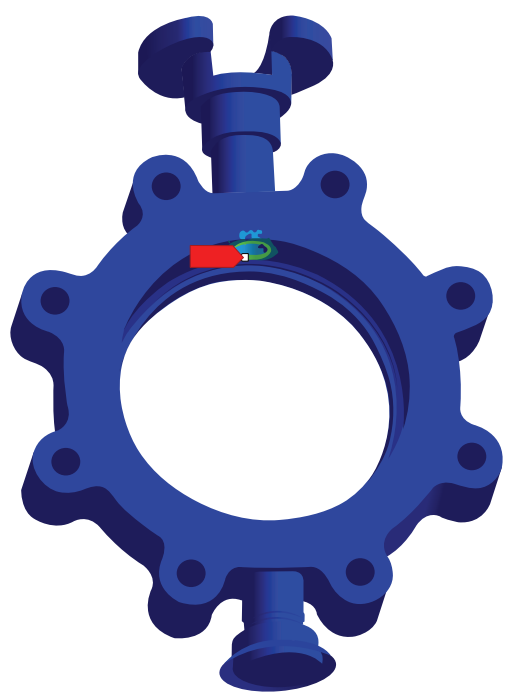

(a) Stress

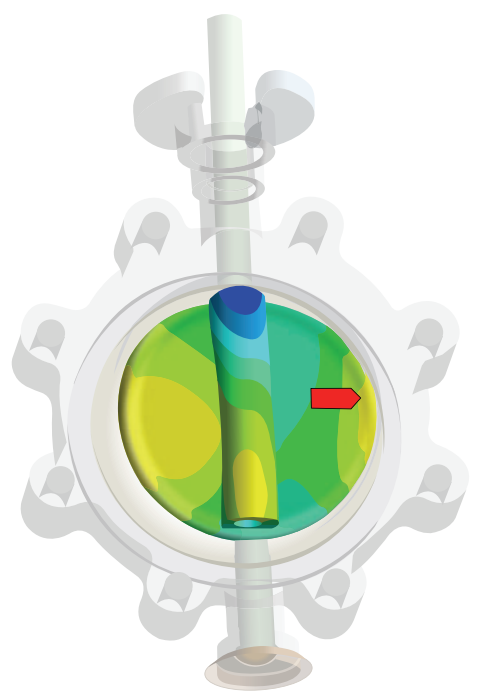

(b) Deformation

FIGURE 7: Results of structural analysis under reverse pressure according to Grade D of the KEPIC MFA.

TABLE 2: Acceleration values of the SSE load according to the KEPIC MFA.

\begin{tabular}{lcc}
\hline Horizontal $(x$-dir. $)$ & Horizontal $(y$-dir. $)$ & Vertical $(z$-dir. $)$ \\
\hline $4.5 \mathrm{G}$ & $4.5 \mathrm{G}$ & $3.0 \mathrm{G}$ \\
\hline
\end{tabular}

all natural frequencies of higher than $33 \mathrm{~Hz}$, as calculated by the modal analysis. The stresses applied in the butterfly valve were calculated under a combined load, that is, an equivalent static force, defined as Grade D by the KEPIC MFA. In the case of Grade D, the combined load, which was subjected at the center of gravity in the butterfly valve, accounted for dead weight, operation load, and SSE load. The operation load occurred under normal and reverse pressures with respect to flow direction in the butterfly valve, and the SSE load was obtained by acceleration values in 3-dimensional directions, as defined in the KEPIC MFA, as shown in Table 2. Figure 7 shows a contour plot of the applied stresses and deformations, and the results are listed in Table 3. A maximal stress of $135 \mathrm{MPa}$ occurred at the contact area between the topside of the stem and the body under a load combination of the dead weight, the operation load under reverse pressure, and the SSE load. The safety factor that described the structural capacity of the butterfly valve was 1.7 in consideration of the allowable stress of the material that was used for the body, Gr. WCB, with a yield strength of $235 \mathrm{MPa}$.

\subsection{Dynamic Analysis}

4.2.1. The Procedure for Response Spectrum Analysis. If the butterfly valve is installed in a pipeline system, its natural frequency could be lower than $33 \mathrm{~Hz}$, and a resonance failure might be expected. In this case, dynamic analysis should be
TABLE 3: Results of structural analysis based on static analysis for Grade D of the KEPIC MFA.

\begin{tabular}{lcc}
\hline & Max. stress $(\mathrm{MPa})$ & Safety factor \\
\hline Normal pressure & 57 & 4.1 \\
Reverse pressure & 135 & 1.7 \\
\hline
\end{tabular}

performed, so that the pipeline system, including the butterfly valve, could show a flexible dynamic motion. The procedure for response spectrum analysis is provided in the KEPIC END [16]. This procedure is based on dynamic analysis, as mentioned in Section 2.2.2. Figure 8 shows a flow chart for the response spectrum analysis.

4.2.2. Characteristics of Dynamic Behavior. For the response spectrum analysis, the natural frequencies of the butterfly valve were obtained by the modal analysis for a full-scale model of a pipeline system, which included this valve. The present study used a simple method to simulate the dynamic behaviors of the full-scale model. This was implemented by modification of the boundary conditions, in which all of the constraints at the valve body were released except for a displacement in the $z$-direction. Figure 9 shows a schematic diagram of the boundary conditions for the modal analysis that was based on the dynamic analysis. Figure 10 shows the natural frequencies at each mode. The 1st and 2nd modes did not occur due to its free-body motion. Meanwhile, the natural frequencies at the $3 \mathrm{rd}, 4 \mathrm{th}$, and 5 th modes were calculated as $24.4,47.9$, and $250 \mathrm{~Hz}$, respectively. The natural frequency at the 3rd mode was lower than $33 \mathrm{~Hz}$, so that the pipeline system including the butterfly valve would be considered flexible and could be affected 


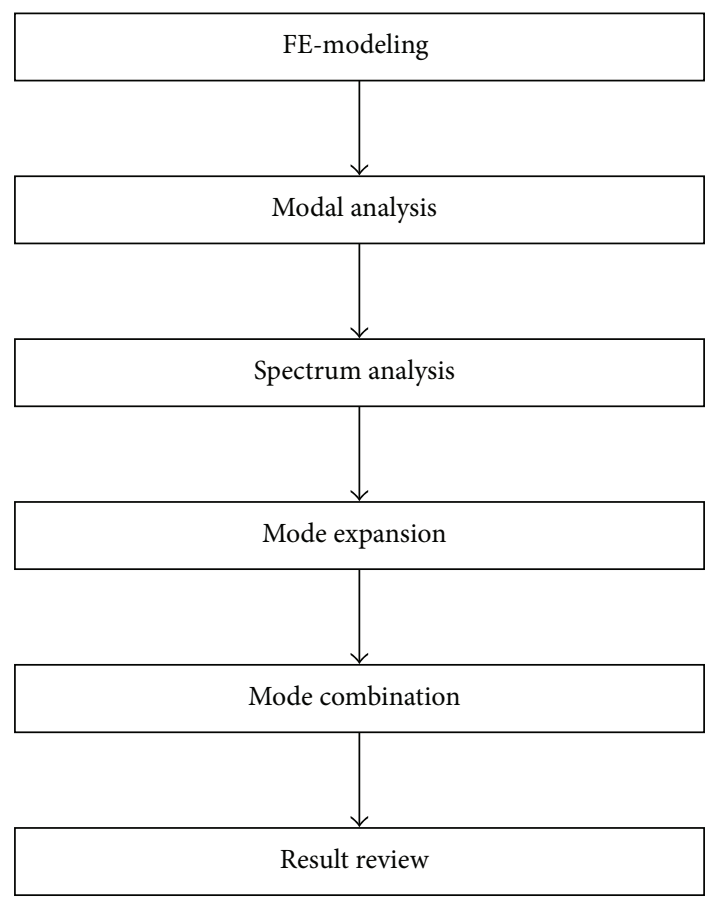

FIGURE 8: Flow chart for response spectrum analysis based on dynamic analysis.

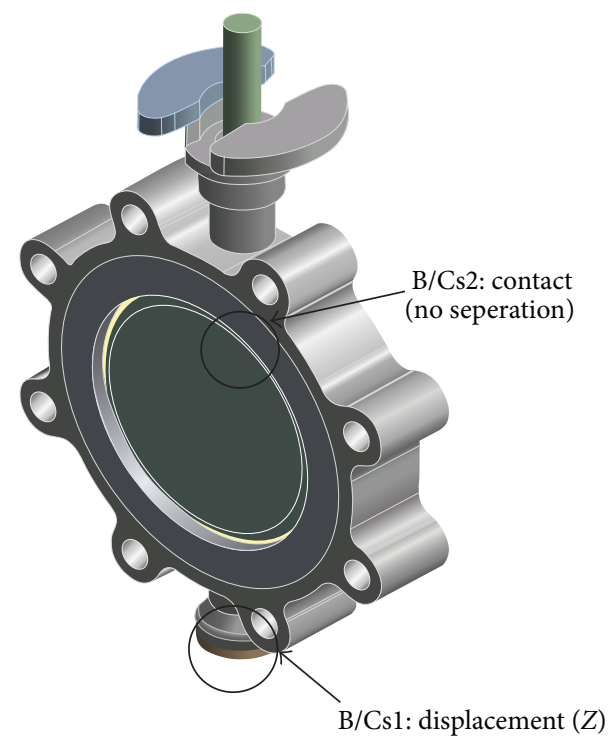

FIGURE 9: Boundary conditions for modal analysis based on dynamic analysis.

by the resonance in the dominant frequency range of an earthquake.

4.2.3. Structural Safety Assessment by Response Spectrum Analysis. For the response spectrum analysis, the responses of stress obtained from each modal response at all significant modes were combined according to the CQC method based on the use of cross-modal coefficients, as shown in (3). The structural analysis that was used to estimate the responses of stress took into account all three load conditions suggested in the KEPIC MFA, that is, RRS (required response spectrum), DRS (design response spectrum), and RIM (required input motion). In general, the DRS is recommended if the RRS and the RIM are not available. In the present study, the load condition regulated in the KEPIC MFA, as shown in Figure 11, was granted to the DRS where a damping ratio of $2 \%$ in the horizontal and vertical directions was taken into account in a case where the valves would be applied to a nuclear power plant. Figure 12 shows the results of the structural analysis, in which the maximal stress of $183 \mathrm{MPa}$ occurred at the contact area between the bottom layer of the stem and the body. The characteristics of dynamic behavior were similar to that for the 3rd mode of the modal analysis, as shown in Figure 10. The structural safety factor was 1.3. Although this result is lower than that in the case of static analysis, the structural safety of the butterfly valve met the requirements of the KEPIC MFA.

\section{Conclusions}

In this study, the structural safety analysis of a 200A butterfly valve for use in a nuclear power plant was performed in static and dynamic ways according to the KEPIC MFA. The results are as follows.

(1) Analytical and experimental modal tests were carried out, and their deviations were taken into account. The initial finite element model was modified to decrease the error range to less than $3 \%$.

(2) The static analysis provided a maximal stress of $135 \mathrm{MPa}$ at the contact area between the topside of the stem and the body under a load combination of the dead weight, the operation load under reverse pressure, and the SSE load. The safety factor for the structural capacity of the butterfly valve was 1.7.

(3) In the case of dynamic analysis, the maximal stress was $183 \mathrm{MPa}$, and the characteristics of dynamic behavior were similar to those for the 3rd mode of the modal analysis. The structural safety factor was 1.3. These values were under the allowable strength for the materials used in the manufacture of the butterfly valve, and, therefore, its structural safety met the requirements of the KEPIC MFA.

The presented findings could be applicable as an index of the structural safety of the butterfly valve based on the seismic qualification in a nuclear power plant. To verify the fatigue requirements according to ASME Section III, the frequency of occurrence based on operating histories should be taken into account, and the fatigue analysis is currently being carried out. These results will be presented elsewhere in the near future. 


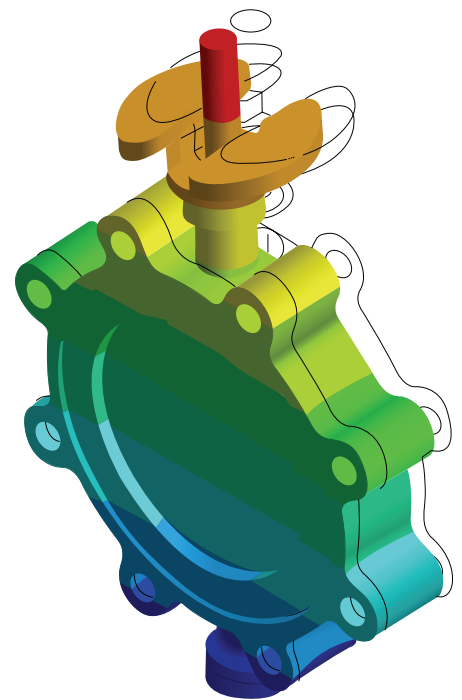

(a) $24.4 \mathrm{~Hz}$ (3rd mode)

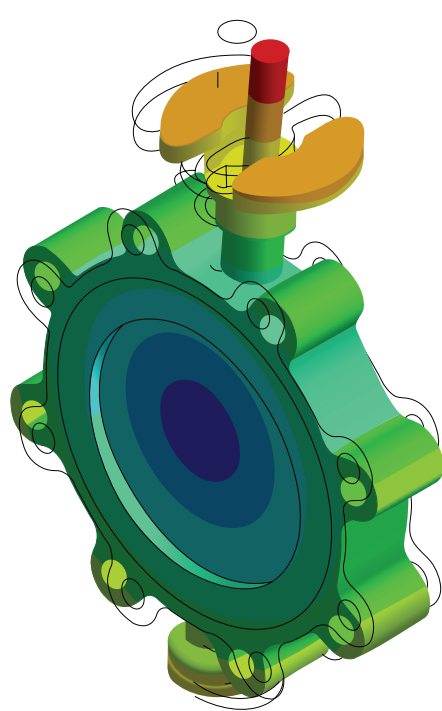

(b) $47.9 \mathrm{~Hz}$ (4th mode)

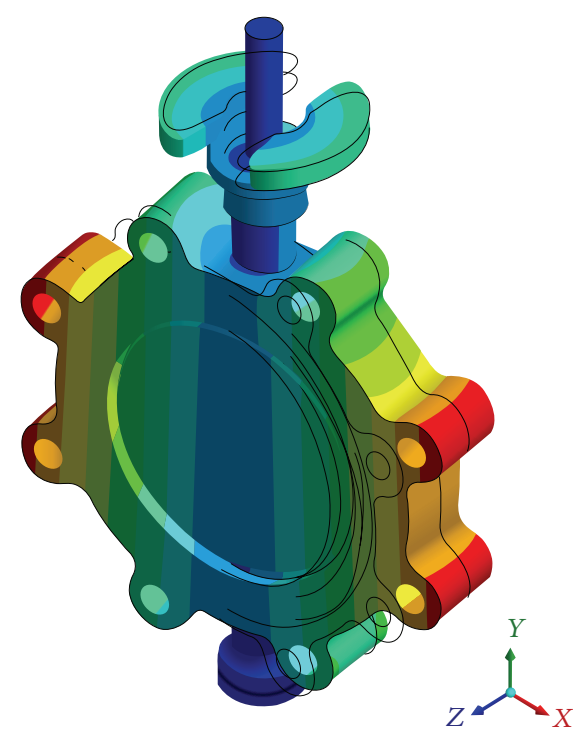

(c) $250.3 \mathrm{~Hz}$ (5th mode)

FIGURE 10: Frequencies at each mode obtained by modal analysis based on dynamic analysis.

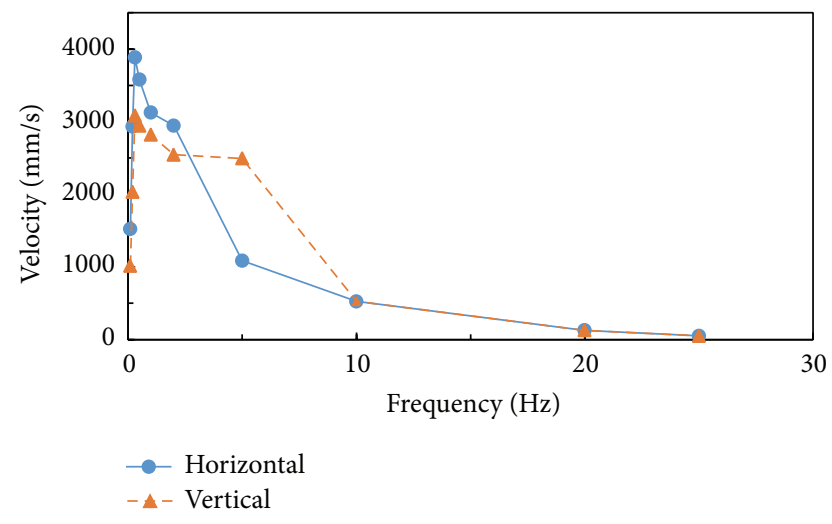

FIGURE 11: Design response spectrum considering a $2 \%$ damping ratio in the horizontal and vertical directions, as stipulated in the KEPIC MFA.

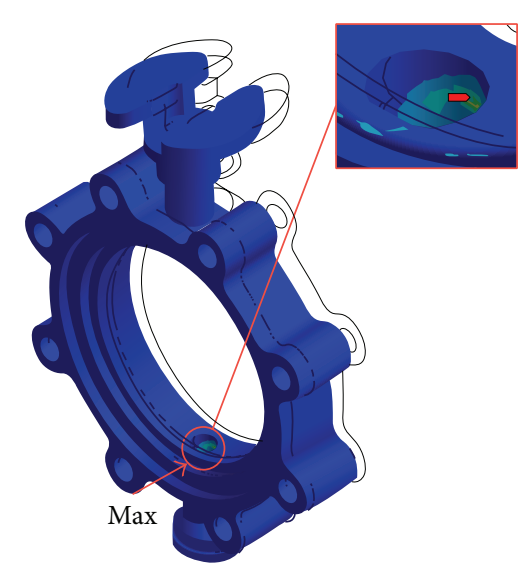

FIGURE 12: Results of structural analysis obtained by dynamic analysis.

\section{Conflict of Interests}

The authors declare that there is no conflict of interests regarding the publication of this paper.

\section{Acknowledgments}

This work was supported by the Human Resources Program (No. 20134030200320) of the Korea Institute of Energy Technology Evaluation and Planning (KETEP), granted financial resource from the Ministry of Trade, Industry \& Energy, Republic of Korea.

\section{References}

[1] International Atomic Energy Agency, Seismic Design and Qualification for Nuclear Power Plant Safety, Safety Series no. 50-SGD15, IAEA, 1992.

[2] C. S. Kim and S. H. Lee, "The economic effects of nuclear power generation using CGE model," Korean Energy Economic Review, vol. 9, no. 2, pp. 129-152, 2010.

[3] M-16 KEPIC MFA, Qualification of Mechanical EquipmentGeneral Requirements, Korea Electric Power Industry Code, 2010.

[4] J. K. Sinha, A. R. Rao, and R. K. Sinha, "Realistic seismic qualification using the updated finite element model for incore components of reactors," in Proceedings of the International Symposium on Seismic Evaluation of Nuclear Facilities, IAEACN-106-29, Vienna, Austria, August 2003.

[5] B. H. Cho, H. H. Jung, S. J. Cho, and C. S. Kim, "The analytical estimation of structural integrity for motor driven auxiliary feedwater pump in nuclear power plants," in Proceedings of the 9th International Conference on Fracture \& Strength of Solids, Jeju, Korea, June 2013.

[6] J. K. Sinha and R. I. K. Moorthy, "Combined experimental and analytical method for a realistic seismic qualification of 
equipment," Nuclear Engineering and Design, vol. 195, no. 3, pp. 331-338, 2000.

[7] U. Sur, "A test verified model development study for a nuclear water chiller using the seismic qualification analysis and test," Nuclear Engineering and Technology, vol. 43, no. 4, pp. 355-360, 2011.

[8] IEEE Std 344-1987, IEEE Recommended Practice for Seismic Qualification of Class $1 E$ Equipment for Nuclear Power Generating Stations, The Institute of Electrical and Electronics Engineers, New York, NY, USA, 1987.

[9] R. E. Spears, "Unique method for generating design earthquake time histories," in Proceedings of the ASME Pressure Vessels and Piping Conference (PVP '08), pp. 3-10, Chicago, Ill, USA, July 2008.

[10] M. J. Jhung and Y. H. Ryu, "Study on dynamic response of mechanical component to earthquake," Journal of Nuclear Science and Technology, vol. 47, no. 11, pp. 1065-1074, 2010.

[11] X. Zhou, R. Yu, and L. Dong, "The Complex-Complete-Quadratic-Combination (CCQC) method for seismic responses of non-classically damped linear MDOF system," in Proceedings of the 13th World Conference on Earthquake Engineering, Vancouver, Canada, August 2004.

[12] Q. Z. Khan, "Evaluation of effects of response spectrum analysis on height of building," in Proceedings of the International Conference on Sustainable Built Environment (ICSBE '10), Kandy, Sri Lanka, December 2010.

[13] ANSYS-Simulation Driven Product Development, http://www .ansys.com.

[14] Brüel \& Kjor Sound \& Vibration Measurement, http://www .bksv.com.

[15] J. K. Sinha and M. I. Friswell, "The use of model updating for reliable finite element modelling and fault diagnosis of structural components used in nuclear plants," Nuclear Engineering and Design, vol. 223, no. 1, pp. 11-23, 2003.

[16] E-5 KEPIC END, Nuclear Electrical and I\&C-Equipment Qualification, Korea Electric Power Industry Code, 2010. 

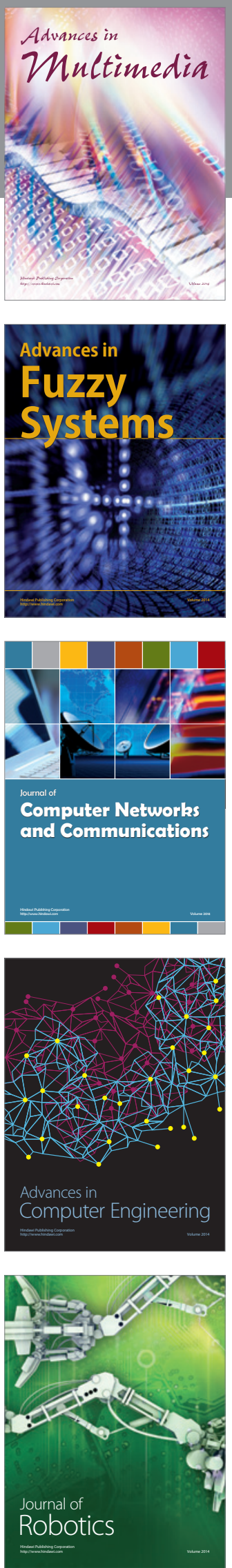

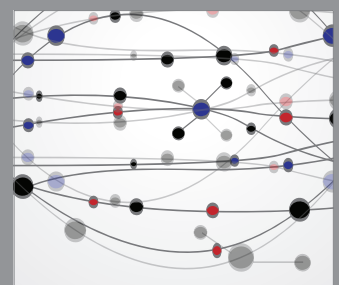

The Scientific World Journal
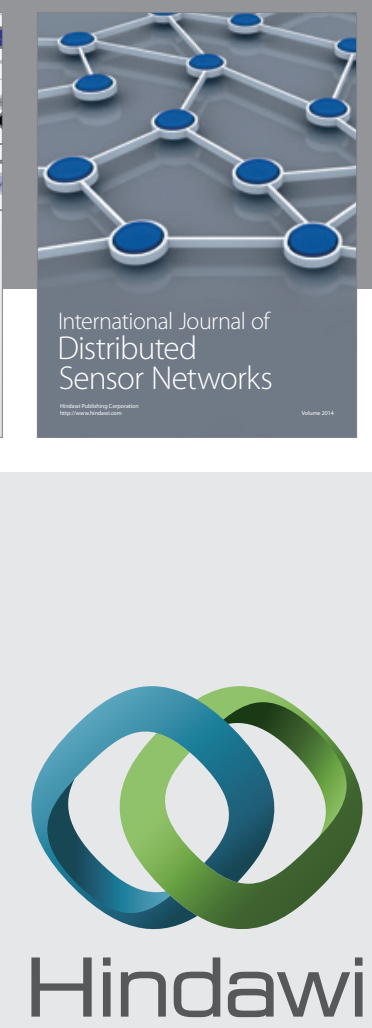

Submit your manuscripts at

http://www.hindawi.com
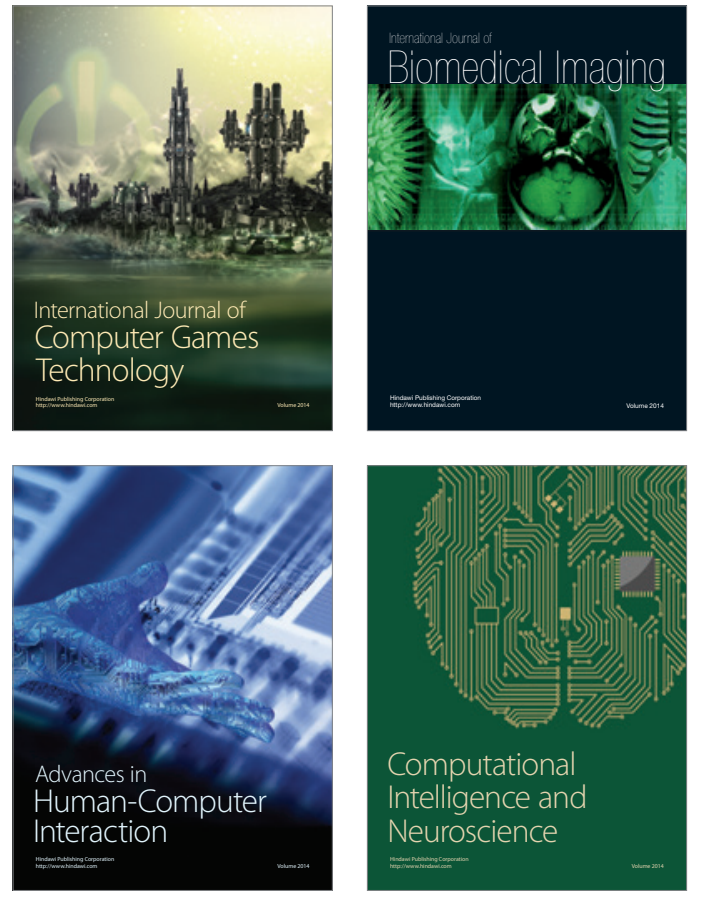
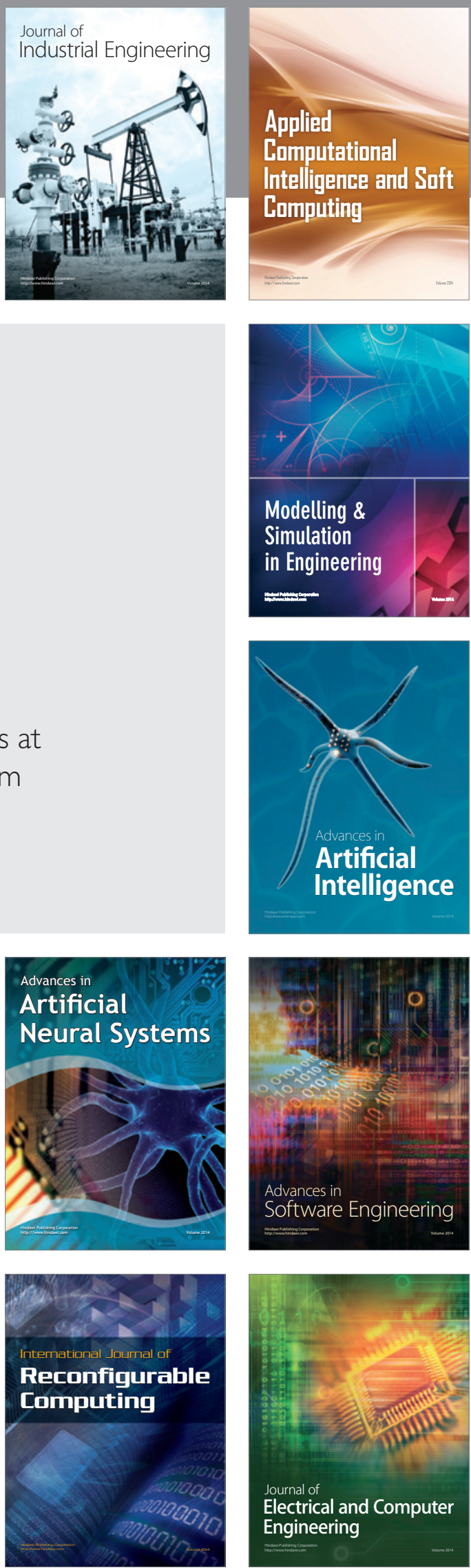